J Chron Dis 1975, Vol. 28, pp. 609-622. Pergamon Press. Printed in Great Britain

\title{
SURVIVAL PATTERNS IN CYSTIC FIBROSIS
}

\author{
Warren J. Warwick, Richard E. Pogue, Hans U. Gerber and \\ CeCIL J. NesBitT
}

Department of Mathematics, The University of Michigan, Ann Arbor, Michigan 48104

(Received in revised form 12 February 1975)

\begin{abstract}
This paper describes the Data Registry System of the Cystic Fibrosis Foundation. Through this system an annual up-dated and corrected data base has been prepared for cystic fibrosis patients seen at U.S.A. Centers from 1966 through 1972.

From the data base, a large number of life table studies are calculated. A study is specified by its data base, the observation period, analysis year (age year or year since diagnosis), the Centers included, and the condition of patients at birth, and possible additional factors such as sex, age at diagnosis, or race. The annual rates of mortality are measured by a force of mortality technique.

Two techniques have been used to appraise the mortality of particular groups, graphing the cumulative survival function for the group together with the cumulative survival function for a comparison group, and calculation of mortality ratios of actual to expected deaths (by an applicable standard mortality table). This latter approach lends itself readily to tests of significance.

For the purpose of calculating mortality ratios, two standard tables have been prepared on the basis of the 1972 Data Base and the 1966-1972 observations. The first of these standard tables is for use with age year studies, and the second is for years since diagnosis studies.

The paper comments on a number of mortality studies by calendar year, by sex, by condition at birth, by age at diagnosis, and of survival from diagnosis of patients diagnosed in 1966-1972. The calendar year studies indicate an improvement trend in the survival experience from 1966 to 1972 but a change may be occurring. The study by sex exhibits a higher female mortality. The $7 \%$ of patients who have meconium ileus at birth show a significantly higher first-year mortality, and a somewhat lower survival rate thereafter even if the first year of life experience is excluded. Mortality data for groups specified by age at diagnosis are given. For patients diagnosed during 1966-1972, there is some indication of better survival than for patients diagnosed prior to 1966.

The continuation of these mortality studies on an annual basis should further our understanding of survival patterns for cystic fibrosis patients.
\end{abstract}

IN THE United States over the last $30 \mathrm{yr}$, the survival of patients with cystic fibrosis has dramatically improved under proper care from a very poor prognosis to an average lifetime of approximately $20 \mathrm{yr}$, with continuing improvement anticipated. Warwick and Pogue have documented this improvement in survival by means of life table studies for a number of years [1]. They have developed a computerized, continuous investigation of the mortality of the children and young adults seen at Cystic Fibrosis Centers throughout the United States supported by the Cystic Fibrosis Foundation (CFF) [2]. From U.S. Centers they receive annual reports on approximately 9000 cystic fibrosis patients, and at the end of $1972 \mathrm{had}$ an aggregate of 15,000 individual 
reports on patients seen at the Centers during 1966-1972. They are also receiving data from other countries, for instance, they have 1400 reports on Canadian patients. Life table studies, on various bases have been compiled annually from these reports. Recently a Data Registry Committee has been appointed to review and extend the work of Warwick and Pogue.* Under the auspices of this Committee the last two authors, who are actuarial mathematicians, have been working with the first two on the further development of the continuous mortality investigation of cystic fibrosis patients.

The CFF Data Registry is recording the mortality experience of patients seen at Cystic Fibrosis Centers and is permitting the observation of trends and variations. In our view, the historical record of progress in improving the survival of cystic fibrosis patients is a valuable end in itself. But information and observations emerging from the Data Registry can also assist patients in fulfilling their lives, and can provide direction to the CFF and other organizations concerned with diminishing this genetic disease. Successful development and utilization of the Cystic Fibrosis Data Registry may well provide a model for use with other diseases of genetic origin.

This paper outlines data collection and management, summarizes the data and describes the methodology of life table studies based thereon, includes tables and figures documenting the mortality experience in the calendar years 1966-1972, and concludes with the major trends observed.

\section{COLLECTION AND MANAGEMENT OF THE DATA}

All Cystic Fibrosis Centers supported by the Foundation are required to provide an annual report on every patient with cystic fibrosis seen by that Center during the preceding year. For new patients, the Center reports the initials of his name; city, state, and zip code of residence; date of birth; date of diagnosis; sex; type of birth (single or multiple); race; condition at birth (normal, with meconium ileus, or with intestinal obstruction); and the patient's status at the end of the year. For previously reported patients, the Center reports only his status at the end of the year. If the patient has died, the Center reports also the date of death and the cause of death. Figure 1 shows the current Cystic Fibrosis Data Registry Annual Report Form. It requires minimal effort to report on this form annually over a period of years.

The reports are checked manually for completeness and correctness. They are then read by an optical scanner onto a magnetic tape which forms the initial data base for the latest completed calendar year, in this paper 1972. The data base is computeredited for completeness and consistency; for example, an inconsistency such as a child diagnosed before the reported date of birth will be identified. A listing of patients with missing or inconsistent information is tabulated. To the extent feasible these data problems are resolved and the initial data base is corrected. The corrected initial 1972 data base is then augmented by data on patients included in the 1971 data base but who are not reported for 1972 because of death, transfer, or lost to follow-up in prior years, or other reason. This provides the final data base, inclusive of data for calendar years 1966-1972, and is referred to as the 1972 Data Base. It is the up-dated basis for case load analyses and life table studies.

*This is a committee of the General Medical and Scientific Advisory Council of CFF and consists of Michael B. Gregg (Center for Disease Control); Richard E. Pogue (Medical College of Georgia); Cecil J. Nesbitt (University of Michigan) and Warren J. Warwick (University of Minnesota). 


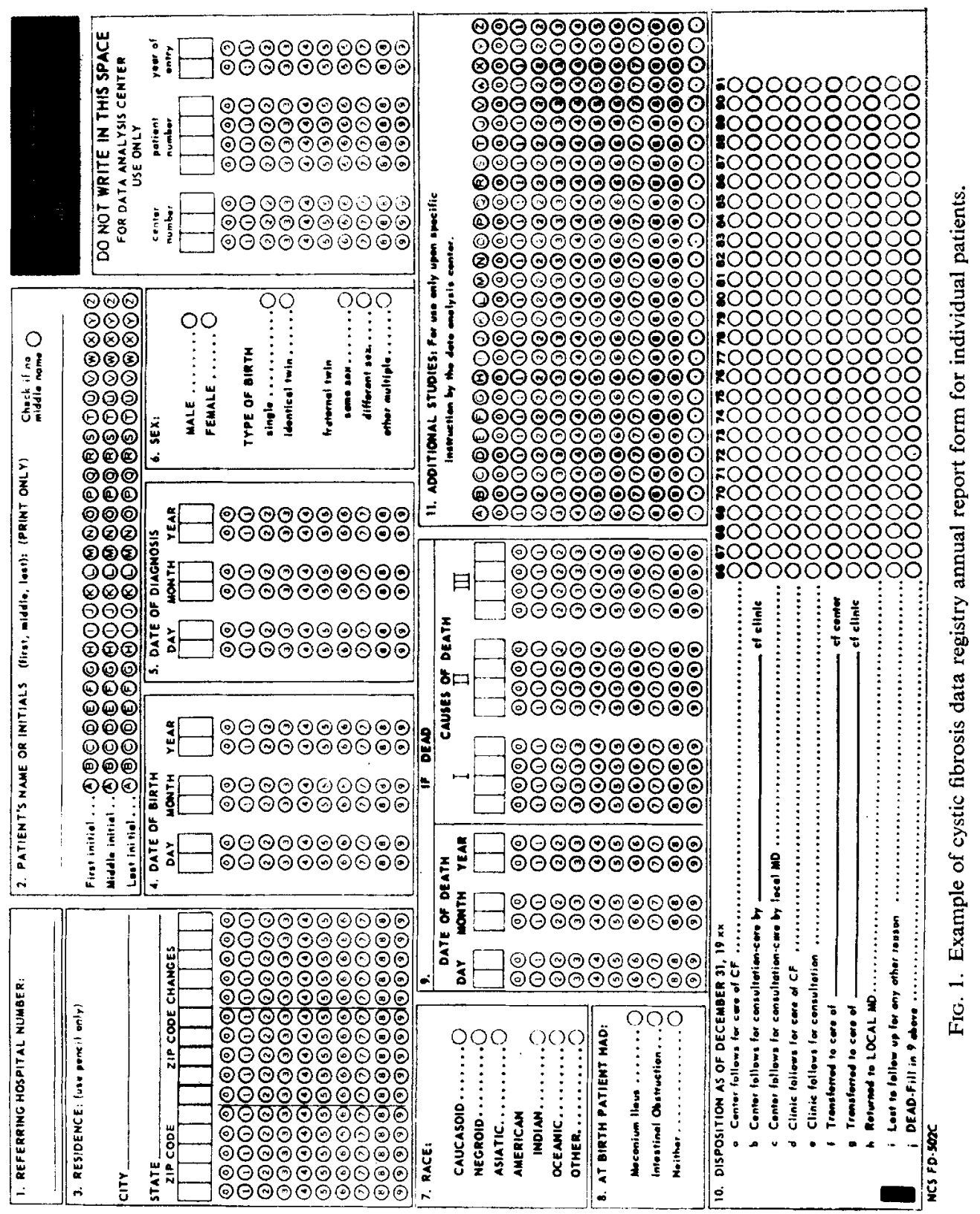

One problem in collecting data from 100 different Centers throughout the United States is the matter of inter-Center duplicates which occur if a patient is seen and reported by more than one Center. The problem has two aspects. A patient may be seen and reported by Center A from 1966-1969 and by Center B from 1970 on. For such a patient two report forms will exist, one for the period with Center $A$ and the other for the period with Center B. This will affect the report statistics but will not create overlapping of mortality data since the patient's data will be counted for Center A for 1966-1969 and for Center B for 1970 on. If, however, Center A continues to 
report for the patient beyond 1969 , an overlapping of mortality data may occur. The extent of such duplication of mortality data has been examined twicc. In 1968, Warwick and Pogue estimated that there was concurrent reporting by more than one Center of the same patient in approximately $2 \%$ of the total reports. In 1974, Warwick and Pogue ran a second test which showed up 153 cases as possible inter-center duplicates. This is approximately $1.5 \%$ of the total cases reported by U.S.A. Centers for 1973 and would have minor effect on national mortality studies.

The Data Registry System has a continuous adjustment process built into it. An incomplete, inconsistent or not-submitted report that could not be included in the 1971 Data Base may be corrected and included in the 1972 Data Base. The report will thereupon be a datum for studies utilizing the 1972 Data Base, in particular, it may be a datum for study of 1971 mortality by means of the 1972 Data Base.

\section{SUMMARY OF THE DATA}

A summary of the 1972 Data Base is given in Table 1. As indicated earlier, the 1972 Data Base contains all individual reports for the period 1966-1972, and may include

Table 1. Summary of 1972 data base

\begin{tabular}{|c|c|c|}
\hline Total number of individual repo & & 15,214 \\
\hline \multicolumn{3}{|l|}{ Distribution by sex: } \\
\hline Male & 7,954 & \\
\hline Female & 7,258 & \\
\hline Not stated & 2 & \\
\hline \multicolumn{3}{|l|}{ Distribution by race: } \\
\hline Caucasian & 14,734 & \\
\hline Negroid & 232 & \\
\hline Indian & 12 & \\
\hline Other, or not stated & 236 & \\
\hline \multicolumn{3}{|l|}{ Distribution by type of birth: } \\
\hline Single & 14,521 & \\
\hline Identical twin & 126 & \\
\hline other twin & 123 & \\
\hline Multiple & 73 & \\
\hline Not stated & 371 & \\
\hline \multicolumn{3}{|c|}{ Distribution by condition at birth: } \\
\hline Meconium ileus & 1,045 & \\
\hline Intestinal obstruction & 198 & \\
\hline Normal & 13,196 & \\
\hline Not stated & 775 & \\
\hline
\end{tabular}


TABle 2. ANAlysis Of CASES RePORTED for 1972 bY U.S.A. Centers (COMPUTED FROM THE 1972 DATA BASE)

\begin{tabular}{|c|c|}
\hline $\begin{array}{l}\text { Number of Centers } \\
\text { reporting for year }\end{array}$ & 97 \\
\hline $\begin{array}{l}\text { Patients reported } \\
\text { under care at } \\
\text { beginning of year }\end{array}$ & 8,200 \\
\hline $\begin{array}{l}\text { PIus } \\
\text { New diagnoses } \\
\text { during year }\end{array}$ & 720 \\
\hline $\begin{array}{l}\text { Plus } \\
\text { Previous diagnoses } \\
\text { first reported }\end{array}$ & 512 \\
\hline $\begin{array}{l}\text { Plus } \\
\text { Former patients } \\
\text { returned to care }\end{array}$ & 140 \\
\hline $\begin{array}{l}\text { Minus } \\
\text { Patients not reported } \\
\text { on for } 1972 \text {, and reports } \\
\text { held for correction }\end{array}$ & 553 \\
\hline $\begin{array}{l}\text { Total Cases reported } \\
\text { for } 1972\end{array}$ & 9,019 \\
\hline $\begin{array}{l}\text { Minus } \\
\text { Deaths during } \\
1972\end{array}$ & 326 \\
\hline $\begin{array}{l}\text { Minus } \\
\text { Transfers to other } \\
\text { centers or local M.D. }\end{array}$ & 353 \\
\hline $\begin{array}{l}\text { Minus } \\
\text { Lost to } \\
\text { follow-up }\end{array}$ & 191 \\
\hline $\begin{array}{l}\text { Patients reported } \\
\text { alive and under care } \\
\text { at end of } 1972\end{array}$ & 8,149 \\
\hline
\end{tabular}

reports from two Centers on a single patient who has transferred from one Center to another. This duplication affects the number of reports but should have minor effect on percentage distributions. From Table 1 one can observe that male patients are more prevalent than females, 52.3 vs $47.7 \%$. As will be seen later, a contributing factor is the more favorable survival of cystic fibrosis males in comparison with that for females. The bulk of the patients, $96.8 \%$ are Caucasian; only $1.5 \%$ are negroid. Identical twins, fraternal twins and other multiple births account for a normal proportion of plural births (approximately $2 \%$ ). Meconium ileus appears as a birth complication for $7.2 \%$ of the patients for which condition at birth was stated.

In Table 2 the number of U.S.A. Centers reporting for 1972 is indicated, and an analysis of the cases reported for 1972 is presented. The number of reporting Centers has increased from 53 in 1966 to 97 in 1972, and the total number of cases reported on for a year has gone from 5288 for 1966 to 9019 for 1972. 
The annual number of new diagnoses at U.S.A. Centers has increased from 598 in 1966 to 720 in 1972 but during that 7-yr period the number of Centers has increased, and the total number of births in the U.S.A. has decreased from 3,606,000 to 3,256,000. A considerable number of the patients first reported for a year have been diagnosed prior to the year of reporting, and there were 512 such reports in 1972.

At year end, a Center will report whether a patient is still under care, has died during the year, has transferred to another Center or to a local M.D., or has been lost to follow-up. In some doubtful cases the Center may not report the patient's year-end status. Meanwhile the patient may have been seen at another Center and will be reported by the new Center. There may be some incompleteness and inaccuracy in the reports from individual Centers, and Table 2 may exaggerate the in and out movement of patients, but under the continuous correction procedures of the system the aggregate data is a reasonably valid basis for mortality studies.

The 326 deaths reported for 1972, and the beginning and year-end totals of 8200 and 8149 patients alive and under care, imply a crude death rate of $4 \%$.

\section{METHODOLOGY OF LIFE TABLE STUDIES}

\section{Specifications of life table studies}

A first specification of a life table study is the Data Base. Normally, the patient data in the latest available Data Base is sorted into various groups in order to make particular life table studies. A next specification for a study is the observation period. Two types of studies have been made-longitudinal and cross-sectional. For longitudinal studies based on the 1972 Data Base, the observation period was taken to be all the years 1966-1972. Cross-sectional studies in contrast specify a single calendar year as the observation period.

Most studies are for all Centers. Special longitudinal studies for individual Centers are carried out when sufficient data is available to provide meaningful results.

Studies may be specificd by selection from the reported data, for example, condition at birth: some studies include all conditions at birth, some are limited to patients with normal birth, some to those who had meconium ileus or to those with intestinal obstruction. Most studies are done in respect to normal birth or on all conditions at birth because the data on meconium ileus and intestinal obstruction cases is too sparse.

Two choices for analysis year have been indicated in earlier studies-analysis by age year in [1], [2] and analysis by years since diagnosis [2], [3]. We are using both types of analysis as each may provide useful information, and we are not prepared to discard one in favor of the other.

Other specifications for life table studies are sex, race, age at diagnosis, and zip code region. For most of the longitudinal and cross-sectional studies, these factors are combined rather than specified, but special studies specifying one or more of the foregoing factors are done each year.

\section{Estimation of rates}

The immediate objectives of a life table study are the estimation of yearly death rates and the calculation of cumulative survival rates therefrom. For studies on the 1972 Data Basis we decided to use the 'force of mortality' technique [4] which utilizes an easily understood concept of patient-years of exposure. The 'force of mortality' at 
a given moment of age is the annual rate of mortality operating for that instant of age. It implies a continuous decrease (negative growth) for the life table cohorts in contrast to the usual mortality rate $q_{x}$ which operates on a discrete year of age rather than on a continuous basis. The average force of mortality $\bar{\mu}_{x}$ for the year of age $x$ to $x+1$ is related to the (discrete) rate of mortality $q_{x}$ by the exponential formula

$$
q_{x}=1-\exp \left[-\bar{\mu}_{x}\right]
$$

(where exp denotes the exponential function, i.e. $\exp y=\mathrm{e}^{y}$ ).

\section{Mortality appraisal, standard tables}

One approach to appraising the mortality of a particular group is to graph the cumulative survival function for that group together with the cumulative survival function for a comparison group. For example, one could compare the graph of the subgroup of patients with normal births with the graph for the combined group of all patients. This gives a quick visual comparison which is often adequate for the purpose on hand.

Another approach, widely used by actuaries, is to establish an appropriate basic or standard table of mortality rates, and by applying these standard rates to the patientyears of exposure in each analysis year for the group under study obtain the number of expected deaths for the group. The ratio of actual deaths to expected deaths is used as an index of the mortality of the group and is referred to as the mortality ratio.

A 1966-1972 Standard Table for Age Year Studies of Cystic Fibrosis Mortality has been prepared from the life table study with the following specifications:

$\begin{array}{ll}\text { Data base - } & 1972 \\ \text { Observation period - } & \text { Longitudinal 1966-1972 } \\ \text { Analysis year - } & \text { Age year } \\ \text { Centers included }- & \text { All U.S.A. Centers } \\ \text { Condition at birth - } & \text { Normal }\end{array}$

Table 3 contains at selected ages the exposures, deaths, estimated annual rates $\hat{q}_{x}$ of mortality, and cumulative survival rates $\hat{s}(x)$ for this study together with annual rates of mortality $q_{x}$ and cumulative survival rates $s(x)$ for the 1966-1972 Standard Table for Age Year Studies. A minimum of smoothing was used to replace the observed average annual forces of mortality by standardized average annual forces lying on a series of linear segments. The latter were obtained by joining points representing the average forces of mortality for age-groups $0-1,1-4,4-7,7-10,10-13,13-16,16$ and above. This was considered to be a slight but sufficient improvement over simply using the weighted average forces as constant forces over the agc-groups for the purpose of calculating expected deaths. Thereby, the force of mortality is represented by a continuous curve rather than by a set of steps.

A 1966-1972 Standard Table for Years since Diagnosis Studies of Cystic Fibrosis Mortality was also prepared from a life table study with the same specifications as for the study underlying Table 3 with the sole exception that the analysis years were years since diagnosis rather than age years. Table 4 presents abridged details.

The mortality and survival rates in Tables 3 and 4 are average rates for cystic fibrosis patients (with normal birth) seen at the Centers during 1966-1972. 


\section{CROSS-SECTIONAL STUDIES}

Each year various cross-sectional life studies are made on the basis of the latest data base. In 1973 such studies were made for each of the calendar years 1966-1972 for all Centers combined. Each study shows for each analysis year the patient-years of exposure, the number of deaths, the annual mortality rate, and the cumulative survival rate, In Fig. 2, cumulative survival rates are graphed for a 1966 cross-sectional study,

TABLE 3. UNDERLYING DATA AND BASIC FUNCTIONS FOR 1966-1972 STANDARD TABLE FOR AGE YEAR STUDIES OF CYSTIC FIBROSIS MORTALITY (SELECTED AGESa)

\begin{tabular}{|c|c|c|c|c|c|c|}
\hline \multirow{2}{*}{$\begin{array}{l}\text { Age Year } \\
x \text { to } x+1\end{array}$} & \multicolumn{4}{|c|}{ Underlying Data } & \multicolumn{2}{|c|}{ Standard Table } \\
\hline & $\begin{array}{l}\text { Patient-yearsb } \\
\text { of Exposure }\end{array}$ & Deaths & $\hat{q}_{x}{ }^{c}$ & $\hat{\mathbf{s}}(\mathrm{x})^{\mathrm{d}}$ & $q_{x}^{e}$ & $s(x)$ \\
\hline $0-1$ & 1018.6 & 76 & .072 & 1.000 & .0719 & 1.000 \\
\hline $5-6$ & 2807.2 & 88 & .031 & .822 & .0343 & .823 \\
\hline $10-11$ & 2249.0 & 113 & .049 & .668 & .0465 & .668 \\
\hline $15-16$ & 1290.5 & 80 & .060 & .521 & .0553 & .518 \\
\hline $20-21$ & 507.7 & 46 & .087 & .379 & .0772 & .378 \\
\hline $25-26$ & 146.4 & 13 & .085 & .250 & .1079 & .236 \\
\hline $30-31$ & 10.0 & 0 & 0 & .123 & .1377 & .125 \\
\hline
\end{tabular}

a Full table may be obtained from the Cystic Fibrosis Foundation.

b For force of mortality method.

c Estimated annual rate of mortality for year $x$ to $x+1$.

$\hat{q}_{x}=1-\exp [-$ deaths/exposure] where exp denotes the exponential function.

d $\hat{s}(x)=$ cumulative survival rate from year 0 to year $x$.

e Standard annual rates of mortality obtained by smoothing as indicated in text.

TABLE 4. UNDERLYING DATA AND BASIC FUNCTIONS FOR 1966-1972 STANDARD TABLE FOR YEARS SINCE DLAGNOSIS STUDIES OF CYSTIC FIBROSIS MORTALITY (SELECTED AGES*)

\begin{tabular}{c|c|c|c|c|c|c}
\hline \multirow{2}{*}{$\begin{array}{l}\text { Year Since } \\
\text { Diagnosis } \\
\mathrm{x} \text { to } \mathrm{x}+\mathrm{I}\end{array}$} & $\begin{array}{c}\text { Uatient-years } \\
\text { of Exposure }\end{array}$ & Deaths & $\hat{\mathrm{q}}_{\mathrm{x}}$ & $\hat{\mathrm{s}}(\mathrm{x})$ & $\mathrm{q}_{\mathbf{x}}$ & $\mathrm{s}(\mathrm{x})$ \\
\hline $0-1$ & 4159.1 & 143 & .034 & 1.000 & .0338 & 1.000 \\
$5-6$ & 3269.9 & 139 & .042 & .841 & .0433 & .039 \\
$10-11$ & 1660.8 & 98 & .057 & .649 & .0558 & .653 \\
$15-16$ & 563.7 & 44 & .075 & .475 & .0710 & .475 \\
$20-21$ & 130.1 & 8 & .060 & .321 & .0891 & .319 \\
$25-26$ & 18.8 & 1 & .052 & .176 & .1194 & .187 \\
$30-31$ & 1.5 & 0 & 0 & .127 & .1487 & .092 \\
\hline
\end{tabular}

*See footnotes to Table 3.

a 1972 cross-sectional study and a 1966-1972 longitudinal study (in all cases in terms of age years and on the basis of the 1972 Data Base for all U.S.A. Center patients who had 'normal' births, i.e. did not have meconium ileus or intestinal obstructions.)

Figure 2 indicates that for the patients observed in these studies, the age for $50 \%$ survival has increased from $10.4 \mathrm{yr}$ in 1966 to $18.1 \mathrm{yr}$ in 1972, an average annual in- 


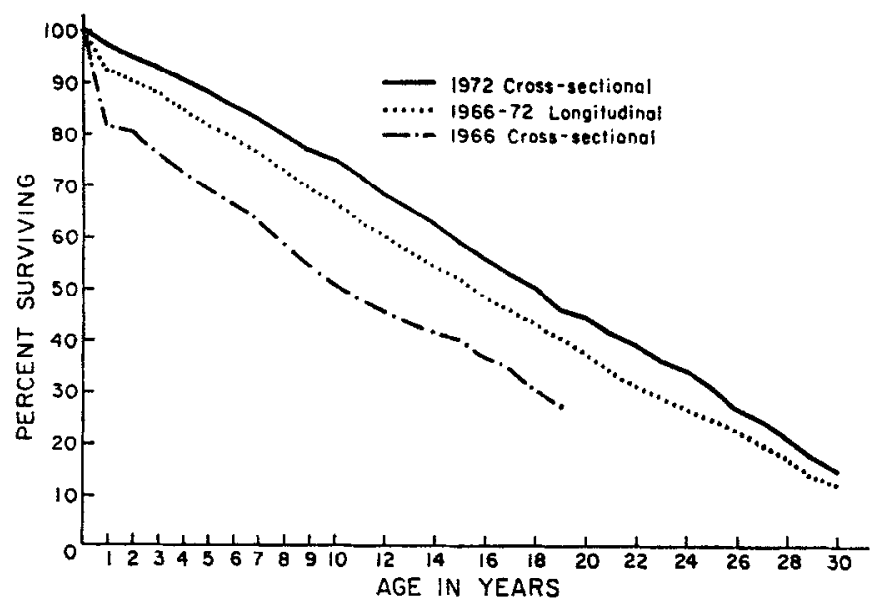

FiG 2. Survival rates 1966-1972. Study specifications: 1972 data base, by age years, all U.S.A. Centers, normal birth.

crease of over one year for each year of study. Because the 1972 survival curve is almost linear, the average years of future lifetime from birth is also approximately $18 \mathrm{yr}$.

Another measure of the mortality improvement over the 7-yr period is given in Fig. 3 which shows the ratios of actual deaths to expected deaths by the 1966-1972 Standard Table for Age Year Studies (see Table 3). This study is on the 1973 Data Base because the corresponding figures on the 1972 Data Base were affected by a computer programming problem which slightly overstated deaths for some of the cross-sectional studies. Over the $7 \mathrm{yr}$ there is a strong decreasing trend in the mortality ratios. However, the mortality ratio for 1973 has been calculated as $90 \%$. If further

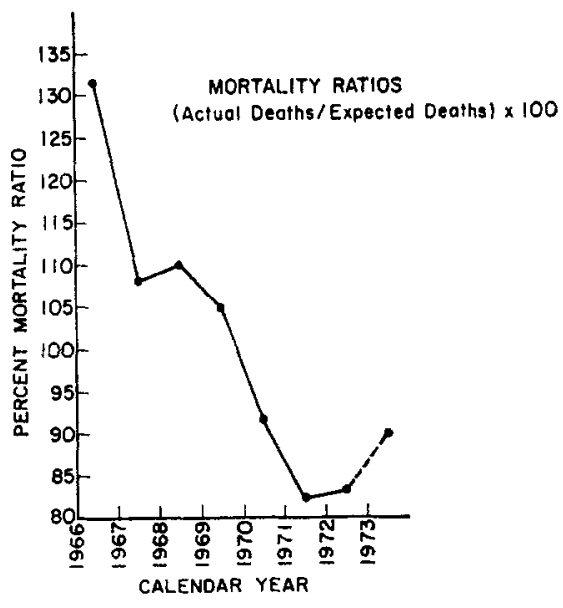

FiG. 3. Mortality ratios by calendar year.

Study specifications - 1973 data base; by age years; all U.S.A. Centers; normal birth; males and females combined.

Expected deaths by 1966-1972 standard table for age year studies. 
study confirms this upturn for 1973 , it will remain to be seen whether this is a temporary fluctuation or reflects some underlying change. We plan to follow this matter closely in the coming years.

\section{LONGITUDINAL STUDIES - BY AGE YEARS}

Many of the specific groups of patients studied had too few members to permit useful studies to be made on a cross-sectional basis. For such groups, studies were longitudinal with observation period extending over the whole 7-yr period, 1966-1972. Comments on a number of such studies are given the following.

$\operatorname{Sex}$

Figure 4 shows survival rates observed over 1966-1972 for males and females combined, compared with the survival rates for males and females separately. At all ages

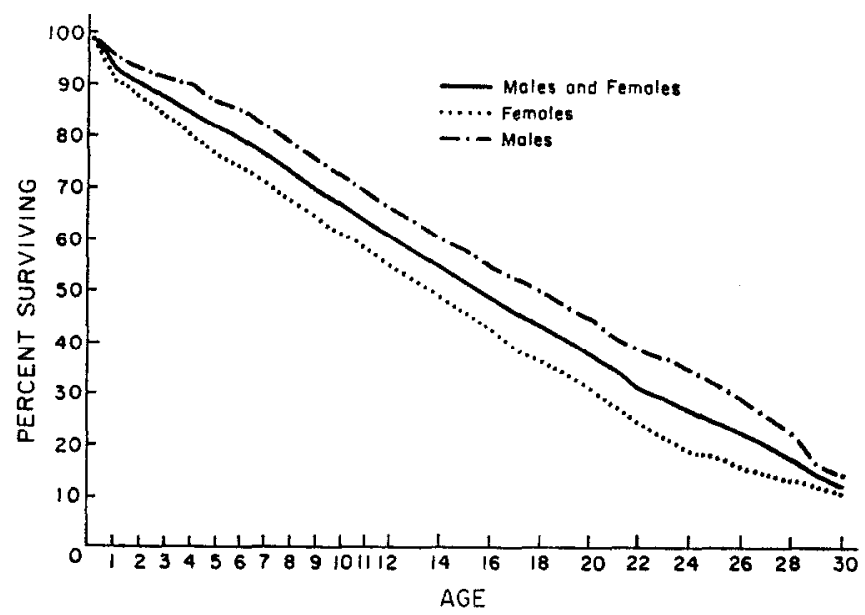

FIG. 4. Survival rates by sex. Study specifications: 1972 data base; 1966-1972 longitudinal; by age years; all U.S.A. Centers; normal birth.

TABLE 5. MORTALITY RATIOS FOR MALES AND FeMALES

\begin{tabular}{l|c|c|c|c|c|c}
\hline \multirow{2}{*}{\begin{tabular}{c} 
Age \\
\cline { 2 - 7 }
\end{tabular}} & $\begin{array}{c}\text { Actual } \\
\text { Deaths }\end{array}$ & $\begin{array}{c}\text { Expected } \\
\text { Deaths }\end{array}$ & $\begin{array}{c}\text { Mortality } \\
\text { Ratio }\end{array}$ & $\begin{array}{c}\text { Actual } \\
\text { Deaths }\end{array}$ & $\begin{array}{c}\text { Expected } \\
\text { Deaths }\end{array}$ & $\begin{array}{c}\text { Mortality } \\
\text { Ratio }\end{array}$ \\
\hline $0-1$ & 29 & 40.2 & 728 & 47 & 35.8 & $131 \%$ \\
$1-7$ & 187 & 255.4 & 73 & 311 & 248.7 & 125 \\
$7-13$ & 313 & 348.0 & 90 & 348 & 307.3 & 113 \\
$13-19$ & 205 & 239.9 & 85 & 212 & 178.5 & 119 \\
$19+$ & 125 & 154.5 & 81 & 107 & 87.9 & 122 \\
& & & & & & \\
Total & 859 & 1038.0 & 83 & 1025 & 858.2 & 119 \\
\hline
\end{tabular}

Study specifications-1972 data base; 1966-1972 longitudinal by age years; all U.S.A. Centers; normal birth.

Expected deaths by 1966-1972 standard table for age year studies of cystic fibrosis patients. 
the survival of males is better than the survival of females, contrary to the usual relation between male and female mortality. This differential is shown another way by mortality ratios in Table 5. For each age group 0-1, 1-7 (pre-school), 7-13 (primary school), 13-19 (secondary school), 19+ (post high school), the mortality ratio for females is substantially higher than the mortality ratio for males. The accumulating data continues to show this mortality differential between males and females.

\section{Conditions at birth}

Figure 5 shows the longitudinal survival curves for patients with the birth complications of meconium ileus and intestinal obstruction, without distinction by sex. The total patient-years of exposure are small for the intestinal obstruction group (543) compared to the meconium ileus group $(2945)$ and the normal birth group $(40,491)$. Although much of the difference between the curves for the meconium ileus group and the normal group lies in the $0-1$ yr mortality, even with this eliminated by calculation of survival curves from age 1, patients with meconium ileus appear to have a slightly poorer cumulative survival curve than do patients with normal birth.

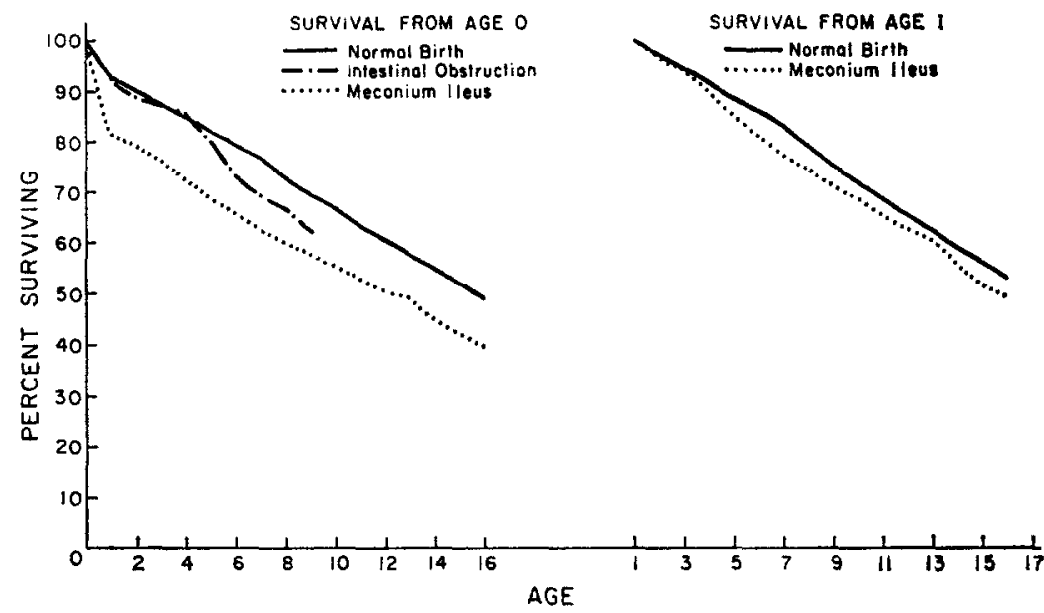

FIG. 5. Survival rates by condition at birth. Study specifications: 1972 data base; 1966-1972 longitudinal; by age years; all U.S.A. Centers.

\section{LONGITUDINAL STUDIES - BY YEARS SINCE DIAGNOSIS}

In the preceding studies, the analysis year has been the age year, with all years since diagnosis combined. In the following studies, the analysis years are years since diagnosis with all ages combined. In the first subsection, studies of patients grouped by age at diagnosis are reported.

\section{Age at diagnosis}

In Table 6 are shown distributions of the patient-years of exposure and the deaths according to the age at diagnosis of the patients. The two distributions are remarkably similar, for instance, $42.4 \%$ of the patient-years of exposure and $41.7 \%$ of the deaths 
TABLE 6. Distributions OF EXPOSURES AND DEATHS BY AGE AT DIAGNOSIS

\begin{tabular}{|c|c|c|c|c|c|c|}
\hline \multirow{2}{*}{$\begin{array}{l}\text { Age at } \\
\text { Diagnosis } \\
x \text { to } x+1\end{array}$} & \multicolumn{3}{|c|}{$\begin{array}{c}\text { Patient Years of Ixposure for } \\
\text { Patients Diagnosed Between } \\
\text { Ages } x \text { and } x+1\end{array}$} & \multicolumn{3}{|c|}{$\begin{array}{l}\text { Deaths of Patients Diagnosec } \\
\text { Between Ages } x \text { and } x+1\end{array}$} \\
\hline & Total & Percent & $\begin{array}{c}\text { Cumulative } \\
\text { Percent }\end{array}$ & Total & Percent & $\begin{array}{l}\text { Cumulative } \\
\text { Percent }\end{array}$ \\
\hline $0-1$ & 17,139 & $42.4 \%$ & $42.4 \%$ & 780 & $41.7 \%$ & 41.78 \\
\hline $1-2$ & 5,733 & 14.2 & 56.6 & 264 & 14.1 & 55.9 \\
\hline $2-3$ & 4,197 & 10.4 & 66.9 & 177 & 9.5 & 65.3 \\
\hline $3-4$ & 2,739 & 6.8 & 73.7 & 122 & 6.5 & 71.9 \\
\hline $4-5$ & 2,102 & 5.2 & 78.9 & 104 & 5.6 & 77.4 \\
\hline $5-6$ & 1,780 & 4.4 & 83.3 & 98 & 5.2 & 82.7 \\
\hline $6-7$ & 1,325 & 3.3 & 86.6 & 62 & 3.3 & 86.0 \\
\hline $7-8$ & 1,063 & 2.6 & 89.2 & 41 & 2.2 & 88.2 \\
\hline $8-9$ & 912 & 2.3 & $9 i .5$ & 40 & 2.1 & 90.3 \\
\hline $9-10$ & 583 & 1.4 & 92.9 & 31 & 1.7 & 92.0 \\
\hline Over 10 & 2,853 & 7.1 & 100.0 & 150 & 8.0 & 100.0 \\
\hline Total & 40,426 & & & 1,869 & & \\
\hline
\end{tabular}

Study specifications-1972 data base; 1966-1972 longitudinal by years since diagnosis; all U.S.A. Centers; normal birth.

are in respect to patients who were diagnosed between ages 0 and 1 , and $78.9 \%$ of the years of exposure and $77.4 \%$ of the deaths are for patients diagnosed before age 5 .

The mortality of patient groups specified by age at diagnosis is being studied but is not ready to be reported. It is established that the mortality is higher at the same time duration from diagnosis for patients diagnosed later in life than for the general body of patients (of whom approximately $80 \%$ are diagnosed below age 5). However, a patient who is diagnosed at say age 15 and is observed over the first 5 yr since diagnosis is much older than the average patient in the first $5 \mathrm{yr}$ after diagnosis, and this factor may account for the observed higher mortality. We plan further study of this question.

\section{Patients diagnosed during 1966-1972 observation period}

The mortality data in Table 4 is in respect to all patients seen at CF Centers during 1966-1972 irrespective of whether the patients were diagnosed prior to 1966 or during 1966-1972. Data for the latter groups was separated out and survival from diagnosis was studied in comparison with the survival by years since diagnosis of all patients. For the group diagnosed during 1966-1972, experience can extend at most to the seventh year since diagnosis and, for comparison, only the experience of all patients during the first $7 \mathrm{yr}$ since diagnosis should be used. The results are given in Table 7 . Part (a) of this table shows mortality data, cumulative survival rates and expected deaths for the group of patients diagnosed during 1966-1972 while part (b) gives for comparison the corresponding items for all patients observed.

The cumulative survival rates are close for the first 2 or $3 \mathrm{yr}$, a not unexpected result since the experience in years 0-2 is mainly on patients diagnosed during 1966-1972. 


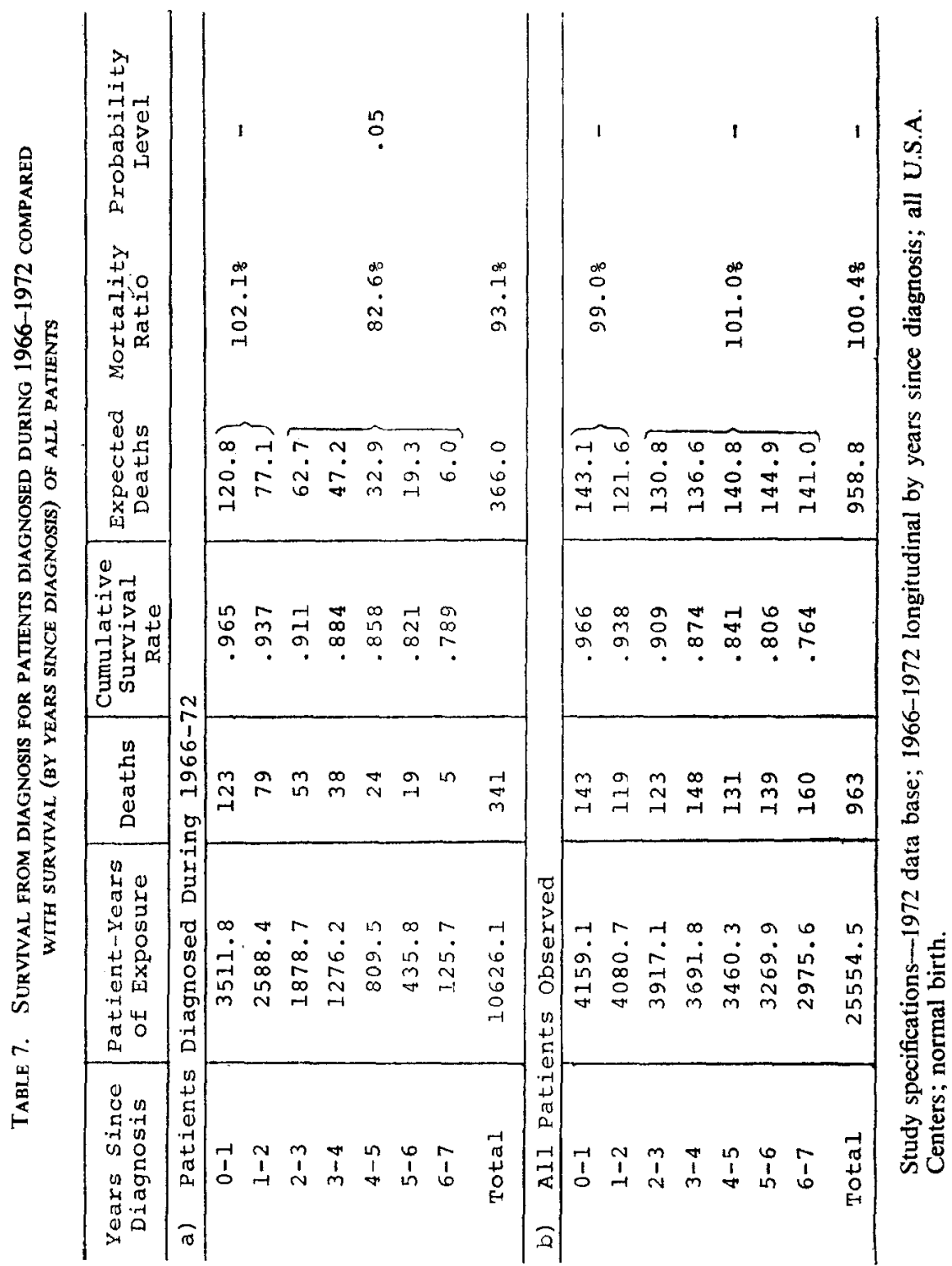


From year 3 onward, the experience of patients diagnosed prior to 1966 becomes a significant element for the part (b) statistics. One would hope that the experience for the more recently diagnosed patients would show some improvement over that for patients diagnosed prior to 1966 , and there is some indication to this effect. For patients diagnosed during $1966-1972$, the mortality ratio for years $0-2$ is $102.1 \%$ and for years $2-7$ is $82.6 \%$. On the assumption that actual deaths for years $2-7$ is a Poisson random variable with parameter equal to the expected number of deaths for year 2-7, the probability of observing a mortality ratio $\leq 82.6 \%$ is less than $5 \%$.

\section{REFERENCES}

1. Warwick WJ, Pogue RE: The prognosis for children with cystic fibrosis based on reasoned approaches to therapy: past, present and future. J Asthma Res 5: 277-284, 1968

2. Warwick WJ, Pogue RE: Computer studies in cystic fibrosis. 5th Int Cystic Fibrosis Conf. Churchill College, Cambridge, 330-332, 1969

3. Swachman H, Redmond A, Khaw Kon-Talk: Studies in cystic fibrosis: report of 130 patients diagnosed under 3 months of age over a 20 yr period. Pediatrics $46: 335-343,1970$

4. Weck FA: The mortality rate and its derivation from actual experience. Rec Am Inst Actuaries 36: $23-54,1947$ 